\title{
Differences in the digestive organ morphology of captive and wild Brown Teal Anas chlorotis and implications for releases
}

\author{
SUZANNE J. MOORE and PHIL F. BATTLEY
}

\section{Summary}

The digestive tract of many animals is morphologically flexible and can adjust over time to make the most efficient use of the foods available. Differences between captive and wild diets often cause large differences in the gut morphology of captive and wild birds. This is potentially an issue when captive-bred birds are used to establish or supplement populations in the wild, such as in the Brown Teal Anas chlorotis, an endangered duck endemic to New Zealand. We compared the size and mass of the digestive organs (proventriculus, gizzard, small intestine, caeca, rectum and liver) of 57 wild, eight captive and four captive-bred released Brown Teal. Captive Brown Teal had much shorter and lighter small intestines and caeca than wild Brown Teal. These differences could reduce the ability of captive-bred teal to efficiently digest a wild diet in the weeks following release, and are likely to contribute to the number of released teal found dead in extremely poor nutritional condition. Increased fibre and diversity in the captive diet together with supplementary feeding post-release are recommended to improve the survival of captive-bred Brown Teal released to the wild.

\section{Introduction}

An efficient and appropriate digestive system is vital for an individual's survival. Eider Ducks Somateria mollisma and Black Scoters Melanitta nigra that feed predominantly on intact hard-shelled molluscs have large muscular gizzards to crush the shells of their prey (Goudie and Ryan 1991), while herbivorous waterfowl such as Gadwall Anas strepera and Brent Geese Branta bernicla have large caeca to break down the large amounts of fibrous plant material they consume (Barnes and Thomas 1987). Having a large gut is energetically expensive (Moss 1972), so birds such as Long-tailed Duck Clangula hyemalis, which eat easily digestible soft-bodied invertebrates, tend to have relatively small gizzards and caeca (Barnes and Thomas 1987).

Over the course of the year an animal's diet may change dramatically due to changing food availability, or differing requirements for energetically demanding reproduction or moult (Krapu 1974, Hartman 1985). The digestive system needs to be morphologically flexible to cope with these changes. Unlike structural components such as bones that essentially do not change in size once an animal is mature, digestive organs can change in size and mass to more efficiently digest different foods (Starck 1999a, b). Changes can be large and rapid; within 5-7 days Red Knot Calidris canutus gizzards can double or halve in mass in response to experimental dietary shifts (Dekinga et al. 2001). As well as changes to gross morphology, the ultrastructure can 
change as organs are up- or down-regulated (Starck 2005). Biochemistry and digestive physiology may also adjust in response to dietary changes (Karasov and McWilliams 2005).

The effects of diet on digestive organ size and efficiency may have important consequences for wildlife management and conservation. Many game bird and threatened species are bred in captivity for release to the wild in attempts to augment existing populations or establish new ones (for example, Brittas et al. 1992, Black et al. 1997), but may be released with digestive organs little suited to their diet in the wild. By experimentally simulating the abrupt change from a captive to a wild diet for handreared Grey Partridges Perdix perdix, Liukkonen-Anttila et al. (1999) found that the birds lost weight dramatically after the dietary change and that a period of 6 weeks could be inadequate for the partridges to adjust to the new diet.

Moss (1972) found that caecal and small intestinal lengths of captive Red Grouse Lagopus lagopus scoticus on an artificial diet decreased, and that decreases continued over several generations in captivity. These decreases were ascribed to the change in diet, particularly the decreased fibre compared with a wild diet, and were thought to become more extreme over the generations as the captive situation actively selected for birds with short caeca. The small intestine and caecum were also smaller in captivereared than in wild Rock Partridges Alectoris graeca, and this was thought to affect the survival of the captive-reared birds on release (Paganin and Meneguz 1992).

In New Zealand, a captive breeding programme is part of the recovery effort for the endangered Brown Teal or Pateke Anas chlorotis (BirdLife International 2000). Between 1968 and 2000 more than 1,800 captive-bred Brown Teal were released into the wild (Moore 2003), but few new self-sustaining populations have been established as a result. Monitoring of recent releases has indicated that some released teal were in very poor nutritional condition prior to death (Moore and Battley 2003a). Although the diet of wild Brown Teal is not particularly well known (Marchant and Higgins 1990), it includes both hard-shelled molluscs (Heather 1980, Moore 2003) and large quantities of terrestrial vegetation (Moore 2003). In contrast, the diet of captive Brown Teal is often based on commercially prepared poultry mash (Hayes 1981). Furthermore captive Brown Teal are likely to have much lower daily energy expenditure than wild teal, causing lower food consumption. It is likely that such large differences between the wild and captive diets (in both quality and quantity) will be reflected in the gut morphology of captive and wild teal, potentially affecting the survival of captive-bred teal released to the wild. This study compares the gut morphology of wild and captive Brown Teal, and discusses the implications of this for the release programme.

\section{Methods}

Brown Teal are a protected species and this research was carried out under permit from the New Zealand Department of Conservation. All carcasses used were from birds found dead by members of the public, captive breeders or Department of Conservation staff.

Wild Brown Teal were sourced from Great Barrier Island $\left(36^{\circ} 18^{\prime} \mathrm{S}, 175^{\circ} 34^{\prime} \mathrm{E} ; 44\right.$ birds), Little Barrier Island $\left(36^{\circ} 20^{\prime} \mathrm{S}, 175^{\circ} 11^{\prime} \mathrm{E}\right.$; two birds), Kapiti Island (40 $50.5^{\prime} \mathrm{S}$, $174^{\circ} 56^{\prime} \mathrm{E}$; two birds) and Northland $\left(35^{\circ} 43^{\prime} \mathrm{S}, 174^{\circ} 4 \mathrm{O}^{\prime} \mathrm{E}\right.$; nine birds) (Table 1 ). Three of the Great Barrier Island teal and both of the Kapiti Island teal had died after a short period (6-7 days) in captivity; the majority of the other Great Barrier Island birds had 
Table 1. Sources of Brown Teal carcasses used in analysis.

\begin{tabular}{llll}
\hline & Male & Female & Unknown \\
\hline Great Barrier Island & $20(5)$ & $22(4)$ & 2 \\
Little Barrier Island & 1 & 1 & \\
Northland & 2 & 1 & 1 \\
Kapiti Island & 3 & $5(1)$ & 1 \\
Captive population & $3(3)$ & 1 & \\
Released captive-bred & & & \\
\hline
\end{tabular}

The numbers in parentheses indicate the number of birds in that category that were emaciated (note that the captive emaciated bird died of age-related emaciation, not neglect). See text for more information.

been killed on roads. Although the Kapiti Island teal are believed to be descendants of a 1968 release, and some teal released in Northland between 1984 and 1995 were recruited into the local wild population (Williams and Dumbell 1996), there have been no releases of captive-bred birds to either Great Barrier or Little Barrier, and all of the wild Brown Teal in this study were wild-bred. The eight captive teal were from four different breeders; one female was wild-bred and had lived in captivity for 8 years, while the remaining seven birds had been bred in captivity. Four captive-bred birds that had died after release to the wild (after 1, 2, 3 and 20 weeks) were also analysed. Ducklings, which were distinguished from juveniles and adults by the presence of down, small body size and incomplete flight feathers, were not included in our analysis. Adult-sized juveniles and adults could not be reliably discriminated throughout the year, so are pooled in this study.

Carcasses were stored frozen and thawed prior to external measurements being taken. Bill length and tarsus were measured with calipers ( \pm o.1 $\mathrm{mm}$ ), wing length of the straightened flattened wing with a steel rule $( \pm I \mathrm{~mm})$ and body mass with a Pesola balance $( \pm I g)$. Wing lengths of birds with broken wing-tips or moulting primaries were excluded from the analysis.

Most carcasses were sexed by plumage and inspection of the gonads. If this was not possible, the presence (male) or absence (female) of the bulla, a bony enlargement at the base of the trachea, was recorded. Some carcasses were badly damaged or decomposed and could not be sexed. One wild female and one captive female were gravid; a second wild female had a brood patch.

We visually assessed the condition of most carcasses, noting the amount of subcutaneous and abdominal fat, and size and shape of the pectoral muscle. We assigned teal into three condition categories: good (visible subcutaneous fat, ranging from little to very much), poor (no visible fat) and emaciated (no visible fat, shrunken breast muscles with a protruding keel). Teal were also classified as emaciated if a postmortem examination by a veterinary pathologist had determined that starvation was the primary cause of death, or if wingfat analysis (Moore and Battley 2003a) had found less than 10\% ulnar lipid. We noted during the dissections that most of the birds we had classified as emaciated had a bloodied or blackened gizzard lining, which has also been observed in European waterfowl and seabirds that have starved (K. Camphuysen, Netherlands Institute for Sea Research, pers. comm. 2003). The three Great Barrier Island teal that had died in captivity were emaciated, while the two Kapiti Island teal that died in captivity were both in poor condition. Teal assigned to either the good or poor condition categories are described hereafter as healthy. Unless specified 
otherwise, all analyses refer to healthy birds only. For these birds, a further distinction based on visual assessment of the amount of subcutaneous and abdominal fat was made. These birds were assigned fat scores of o (no fat visible), I (small amounts of fat), 2 (quite large fat deposits) or 3 (very large fat deposits).

As this study was on an endangered species, sample sizes were limited by the available carcasses, which were often recovered in poor condition, and many of which were desired for other purposes (including post-mortem pathology, taxidermy, museum collections and traditional uses). This resulted in variable sample sizes between organs and in small samples of captive and captive-bred released teal. Many carcasses were partial, so the complete set of digestive organs could not always be collected.

\section{Digestive organ morphology}

The entire digestive tract plus liver was removed, tied around the top of the oesophagus and lower end of the rectum to prevent the loss of gut contents, weighed, labelled and stored frozen in plastic bags.

Before analysis, the digestive organs were thawed, and the liver removed. Fat and mesenteries were removed from the digestive tract, which was laid out, straightened but not stretched, on a wet surface. Proventriculus length and gizzard length, width and depth were measured with calipers $( \pm 0.1 \mathrm{~mm})$. Lengths of the small intestine from the gizzard to the anterior junction with the caeca, each caecum to the junction with the small intestine, and the rectum from the anterior caecal junction were measured using a steel rule $( \pm 1 \mathrm{~mm})$.

The remaining tract was separated into six sections: oesophagus, proventriculus, gizzard, small intestine (gizzard to anterior junction of caeca), rectum (anterior junction of caeca to cloaca) and caeca (which were removed separately). The oesophagus, proventriculus, gizzard, rectum and caeca were cut open and the contents scraped out and retained in pre-weighed labelled containers. The small intestine was cut into lengths and squeezed three times to remove any contents. If the contents were very gritty or fibrous and could not be removed by squeezing, the small intestine was cut open and scraped out. The contents were weighed $( \pm 0.01 \mathrm{~g})$ and frozen, and any intestinal parasites found were stored in $70 \%$ ethanol for later analysis. Body weight for intact birds was calculated as the fresh carcass weight minus the mass of the gut contents (no weight could be recorded for partial carcasses).

All organs were weighed fresh $( \pm 0.01 \mathrm{~g})$ in labelled, pre-weighed aluminium foil dishes, then dried in ovens at $60^{\circ} \mathrm{C}$. After cooling in a desiccator, samples were reweighed, and the process repeated until each achieved a constant mass.

Data were analysed using Systat 1o (SPSS Inc.)

\section{Results}

On average $( \pm S D)$, wild female Brown Teal weighed $482 \pm 76 \mathrm{~g}(n=20)$ and males weighed $564 \pm 58 \mathrm{~g}(n=17)$. The average mass of captive females was $565 \pm 96 \mathrm{~g}(n$ $=4)$; the three captive males weighed 531, 553, and $668 \mathrm{~g}$. Males were significantly heavier than females (controlling for source: $F_{1,40}=9.990, P=0.003$ ). Captive birds tended to be heavier than wild birds (least squares means controlling for sex: captive mass $=578 \pm \mathrm{SE} 27 \mathrm{~g}$, wild mass $=524 \pm 12 \mathrm{~g} ; F_{1,40}=3.327, P=0.076$, when sex 
and source are included as factors in ANOVA; first-order interactions between sex and source were not significant in any analyses, and consequently analyses were rerun without the interaction). Captive teal were also fatter than wild birds. Very large fat deposits were observed in some captive birds and the visually assigned fat scores (which correlate well with actual adiposity; Moore and Battley 2003a) of captive Brown Teal were higher than those of wild teal (Mann-Whitney $U$-test, $U_{7,46}=252, P=$ O.OII).

Wild Brown Teal had muscular gizzards containing grit, long small intestines and well-developed caeca. Digestive organs made up less than 10\% of the birds' total mass, with an average fresh weight of $43 \mathrm{~g}$. For these birds, we investigated whether lengths or dry masses of different digestive organs were correlated with each other, with body mass or with structural size variables (Table 2). The lengths and the dry masses of the small intestine, caeca and rectum were highly correlated, probably due to their similar roles in the digestive process, absorption of nutrients and water. The liver was the only organ whose dry mass was correlated with body mass, while gizzard volume and dry mass were strongly correlated with structural size (bill, wing and tarsus lengths). The lengths (and volume for the gizzard) of each part of the digestive tract were highly correlated with their dry masses, with Pearson's correlation coefficients from 0.462 for rectum to 0.965 for gizzard (in all cases $P<0.001$ ).

We tested for differences in gut morphology of wild and captive teal, using ANCOVA, taking source (whether the bird was captive or wild; the wild-bred female which had lived in captivity for 8 years was included as captive) and sex as factors, with

Table 2. Relationships between digestive organs, body mass and body size in wild Brown Teal, not including emaciated birds.

\begin{tabular}{|c|c|c|c|c|c|c|}
\hline & Proventriculus & Gizzard & Small intestine & Caeca & Rectum & Liver \\
\hline \multicolumn{7}{|l|}{ Organ size } \\
\hline Gizzard & 0.249 & & & & & \\
\hline Small intestine & $0.462^{* *}$ & $0.371^{*}$ & & & & \\
\hline Caeca & $0.356^{*}$ & $0.377^{*}$ & $0.600^{* * *}$ & & & \\
\hline Rectum & $0.319^{*}$ & 0.186 & $0.53^{* * *}$ & $0.396^{*}$ & & \\
\hline Body mass & $0.391^{*}$ & 0.285 & $0.397^{*}$ & 0.200 & $0.341^{*}$ & \\
\hline Bill length & 0.281 & $0.378^{*}$ & 0.228 & $0.351^{*}$ & -0.019 & \\
\hline Wing length & $0.439^{* *}$ & $0.422^{* *}$ & 0.308 & 0.267 & 0.301 & \\
\hline Tarsus length & $0.326^{*}$ & $0.356^{*}$ & $0.428^{* *}$ & $0.395^{* *}$ & 0.042 & \\
\hline \multicolumn{7}{|l|}{ Organ mass } \\
\hline Gizzard & 0.236 & & & & & \\
\hline Small intestine & 0.169 & 0.004 & & & & \\
\hline Caeca & 0.180 & 0.179 & $0.576^{* * *}$ & & & \\
\hline Rectum & 0.110 & 0.181 & $0.716^{* * *}$ & $0.607^{* * *}$ & & \\
\hline Liver & $0.476^{* *}$ & 0.218 & 0.275 & $0.482^{* *}$ & 0.263 & \\
\hline Body mass & 0.306 & 0.311 & 0.000 & 0.140 & 0.011 & $0.586^{* *}$ \\
\hline Bill length & 0.084 & $0.389^{* *}$ & -0.054 & 0.266 & -0.003 & 0.081 \\
\hline Wing length & 0.140 & $0.352^{*}$ & -0.021 & 0.227 & 0.154 & 0.291 \\
\hline Tarsus length & 0.120 & $0.325^{*}$ & 0.085 & 0.065 & 0.017 & $0.428^{*}$ \\
\hline
\end{tabular}

Values are Pearson correlation coefficients; significance levels are from Bonferroni probabilities. Data used were lengths (most organ size measurements), volume (gizzard size), dry masses (all organ masses) and fresh mass (body mass). Caeca values were for both caeca combined.

${ }^{*} P<0.05 ;{ }^{* *} P<0.01 ;{ }^{* *} P<0.001$. 
body mass (and for the gizzard, structural size) as a covariate. We could not test for differences in proventriculus due to our small sample size for captive birds $(n=2)$, but the values we did have for captive birds were within I SD of the mean of wild birds (Table 3). Cumulative probability plots were used to test for normality; only liver masses required a log transformation. There was no difference in gizzard mass or volume between captive and wild teal. Average lengths and masses of the small intestine and caeca were significantly larger in wild than in captive birds. Heavy teal had the largest liver mass, but there was no difference in liver size between captive and wild birds when body mass was included as a covariate.

Gut parasites (cestodes, trematodes and nematodes) were found in wild birds from Great Barrier Island (6) and Northland (4), and in one of the captive birds. There was no significant difference in lengths or dry masses of the small intestine and caeca between wild teal with discernible gut parasites and those with no gut parasites evident, either using Student's $t$-test or using ANCOVA with body mass as a covariate.

We also assessed the digestive organs of two additional groups of teal: emaciated wild birds and captive-bred birds that were released or emaciated. Of the latter group, one died in captivity of age-related emaciation (at 18 years of age), and another had become trapped in vegetation shortly after release and was found dead within a week of release, leaving only three birds believed to have fed in the wild. Of these three, two had starved after less than 4 weeks in the wild, and the third had lived in the wild for 20 weeks before being recaptured and transferred to a pen, where it was killed by a dog within a week (N. Miller, Department of Conservation, pers. comm. 2003). In general, the emaciated wild, and released or emaciated captive birds had lighter gizzards than most healthy wild and captive teal (Figure 1). They also had lighter small intestines and caeca than the majority of the healthy wild teal, similar in mass to those of the healthy captive teal. The exception to this was the captive-bred teal that had lived in the wild for 20 weeks; its digestive organs were similar to those of healthy wild teal.

\section{Discussion}

Compared with healthy wild Brown Teal, captive teal were heavier and fatter, and had correspondingly larger livers. Increased liver weight is associated with increased feeding in several waterfowl species (Ankney 1977, DuBowy 1985) and is probably due to the liver's role in protein metabolism and lipid storage (Ankney and Scott 1988, Kehoe et al. 1988).

There was no difference in mean gizzard size between captive and wild Brown Teal, but the small intestine and caeca of the captives were smaller than those of healthy wild teal, and were comparable in length and mass to those of emaciated wild birds (Figure 1). The small intestine and caeca have similar functions: the enzymatic digestion and absorption of the digestive end products (Klasing 1998). Although gut parasites can cause an increase in the host's intestinal mass (Kristan and Hammond 2000), no effect of gut parasites on intestinal length was apparent in wild Brown Teal.

Dietary factors such as food intake and diet type (fibre content and degree of softness/hardness) affect digestive organ sizes across a wide range of bird species (Battley and Piersma 2005). The captive diet for adult teal is usually based on either commercially prepared poultry mash (K. Evans, Brown Teal captive breeding 


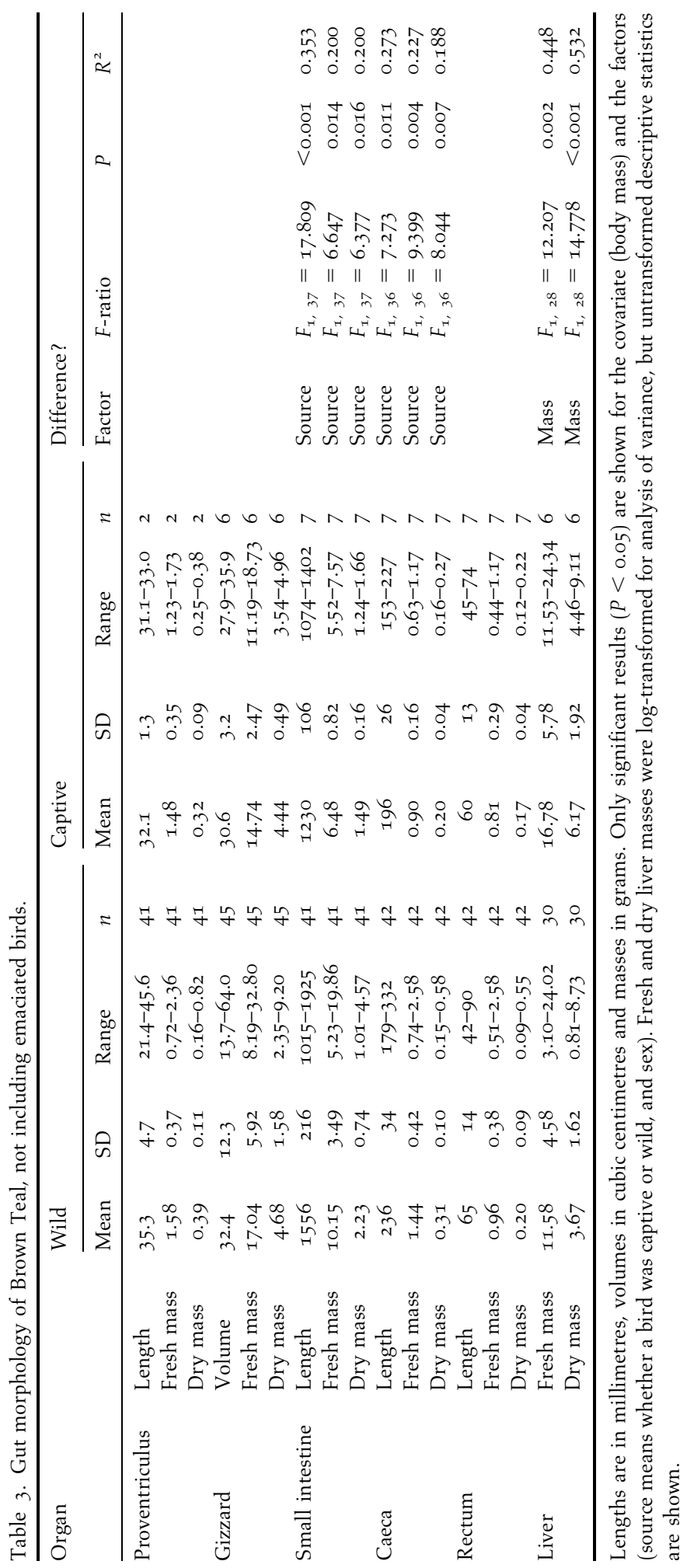



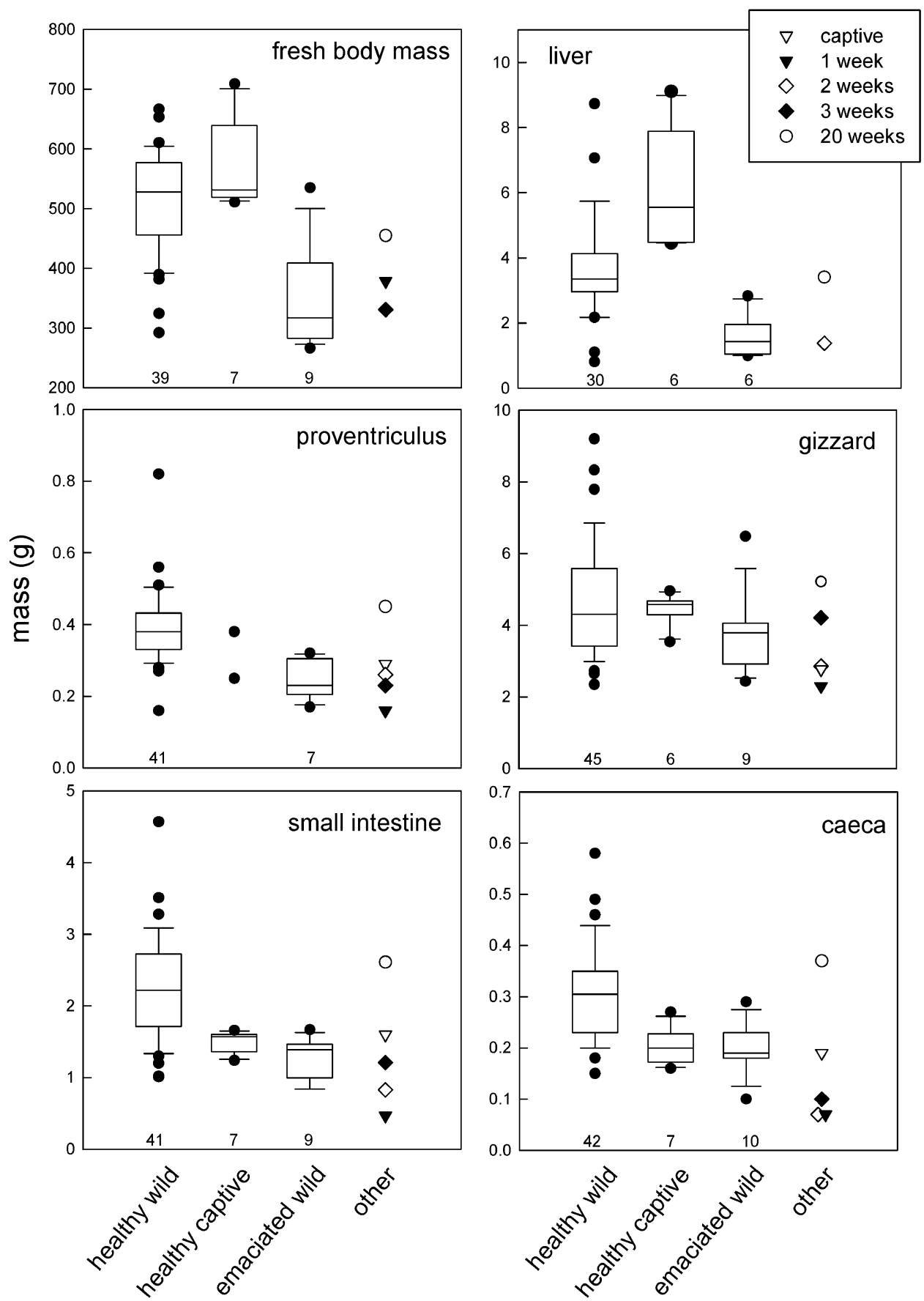

Figure 1. Fresh body mass and digestive organ dry mass of healthy wild, healthy captive, emaciated wild and 'other' Brown Teal. Healthy birds were those assigned to either the good or poor condition categories. The 'other' category includes one emaciated captive Brown Teal, and four captive-bred released teal that died after $1,2,3$ and 20 weeks in the wild respectively (see legend). Boxes enclose the median, with $25^{\text {th }}$ to $75^{\text {th }}$ percentiles, and whiskers show the 1oth and goth percentiles. Sample size is shown below each box. 
co-ordinator, pers. comm. 2003; N. Hayes, Brown Teal captive breeder, pers. comm. 2003) or Massey University Teal pellets, both low in fibre (maximum 6\% fibre in Sharpes Stockfeed Ltd, Carterton, New Zealand hi-lay mash), although some breeders use commercially prepared trout or calf pellets (K. Evans, pers. comm. 2003). In contrast, the diet of wild Brown Teal includes hard-shelled molluscs, hard seeds and terrestrial vegetation (Heather 1980, Moore 2003).

Compared with the captive diet, the 'wild' diet requires higher intake rates and more digestive processing to provide the necessary energy and nutrients, due to its higher proportion of constituents such as cellulose and shell that are difficult or impossible to digest. These dietary differences are likely to have resulted in the larger small intestine and caeca we observed in wild Brown Teal relative to captive birds. Increases in small intestinal and caecal length and mass often follow a decrease in food quality (Miller 1975, Moss and Trenholm 1987, Kehoe et al. 1988) and/or increasing food intake (Drobney 1984, Heitmeyer 1988), and may be observed within 5 days of a diet change (Kehoe et al. 1988). Although more metabolically expensive and heavier, long guts improve an animal's ability to survive on poor food (Moss 1983). A large small intestinal volume may also permit the passage of mollusc shell fragments through the gut (Barnes and Thomas 1987). Unlike the Red Knot that requires a large muscular gizzard to crush a diet consisting mainly of hard-shelled molluscs (van Gils et al. 2003), the omnivorous wild Brown Teal may rely more on a well-developed intestine and caeca to efficiently digest its varied diet.

The unnatural diet of captive teal and the resulting reduction in small intestines and caeca place newly released captive-bred teal at a disadvantage. Released Brown Teal may be unfamiliar with the wild food available, and initially unwilling to try new foods, either because they are suspicious of them (Liukkonen-Anttila et al. 1999), because they are reluctant to eat foods unsuited to their digestive organs (Piersma et al. 1993), or, for some foods, because they have had no training in how to access them (see Moore and Battley 2003b). When they do start feeding on wild foods, their guts may be inefficient at digesting them. Although digestive organs can rapidly change size to accommodate a new diet, it may take more than six weeks on the new diet for them to fully adapt (Liukkonen-Anttila et al. 1999). When captive Mallards A. platyrhynchos were put on a high-fibre diet, their small intestine and caeca increased in mass and length, more closely approximating that of wild Mallards (Miller 1975, Kehoe et al. 1988). The captive Mallards achieved their maximum gizzard, intestinal and caecal mass after 10 days on the high-fibre diet, but caecal and intestinal lengths were still increasing at 25 days when the experiment finished (Kehoe et al. 1988).

When birds change from a high- to low-quality diet, they need to consume more food to compensate for the reduced digestibility (Miller 1975). In spite of a higher intake rate and the constant temperature regimes of their captive situation, captive Grey Partridges decreased in body mass in the first week of a high-fibre diet, and stabilized at a lower level than that of control (low-fibre diet) birds (Liukkonen-Anttila et al. 1999). This is probably because immediately after a dietary switch the assimilation efficiency of birds is often low (Afik and Karasov 1995, Hilton et al. 2000) as a consequence of their gut size and biochemistry being mismatched to the new diet.

Captive-bred released Brown Teal face higher energy demands than the birds typically used in captive dietary studies. Released teal are likely to need more energy for thermoregulation due to lower ambient temperatures. They may disperse over quite large distances; three captive-bred released teal were shot more than $70 \mathrm{~km}$ 
from their release site within 4 months of release (New Zealand bird banding office database). Reacting to predators or aggressive competitors may also be energy-demanding.

At least initially, captive-bred released teal are likely to be poorly suited to digesting a wild diet, unfamiliar with what food there is available, and subject to higher metabolic costs than most captive birds used in diet experiments. If so, this should manifest as teal in poor nutritional condition. Monitoring of Brown Teal releases at four sites in 2001 and 2002 found that at least eight captive-bred birds $(23 \%$ of those released) starved within 6 weeks of release (Moore and Battley 2003a).

A simple test of whether captive Brown Teal were adapted to a wild-type diet would be to feed groups of captive teal diets that differed in the amount of fibre for several months, then measure the birds' digestive efficiency and digestion rate when switched to a wild-type diet. This would effectively determine which captive diets best prepared them for wild foods, without the need to release and recapture the birds. In the meantime we would encourage any individuals or institutions holding captive Brown Teal to keep good records of the diets that the birds are being fed and to freeze any casualties so that they are available for future organ analyses.

Even if increased fibre in the diet allows captive-bred teal to be released with digestive organs suitable for a diet in the wild, behavioural deficiencies (such as in recognition of wild foods) may still limit survival. Providing accessible and familiar supplementary food to birds post-release could help ease the transition from the captive to a wild diet and should also be trialled to see whether post-release survival of captive-bred Brown Teal can be improved.

A largely unaddressed issue for reintroduction programmes in which captive breeding has taken place over many generations is whether (inadvertent) selection for 'captive guts' could limit the genetic capacity of the released birds to respond quickly to a change in diet. The captive Brown Teal population was apparently descended from 76 wild birds collected from Great Barrier Island between 1960 and 1987, but no records were kept of the age or parentage of breeding birds (Dumbell 2000). The captive-bred birds in our study are an unknown number of generations removed from the wild and could have been subject to selective pressure favouring small guts and caeca (see Moss 1972). It is possible that genetic factors contributed to the differences we observed between captive and wild Brown Teal. A small number of wild Great Barrier Island teal were recently added to the captive population (Davis and $\mathrm{O}^{\prime}$ Connor 2002). Combined with well-planned pairings, this should help decrease any genetic differences between wild and captive birds.

\section{Acknowledgements}

S. J. M.'s work was supported by a Julie Alley bursary, a Massey University scholarship and the Golden Plover Award from the Wetland Trust. We thank Department of Conservation staff, Kevin Evans, Eric Fox, Brian Gill, Raewyn Empson, Noel Hyde, Alan Tennyson, the Institute of Veterinary Animal and Biomedical Sciences, Massey University (IVABS), Willowbank Wildlife Park, Wellington Zoo and Ngati Rehua for access to the Brown Teal carcasses. Thanks go to Ian Henderson for statistical advice, and Ian Henderson, Ed Minot, Geoff Hilton and an anonymous referee for comments that improved this paper. 


\section{References}

Afik, D. and Karasov, W. H. (1995) The trade-offs between digestion rate and efficiency in warblers and their ecological implications. Ecology 76: 2247-2257.

Ankney, C. D. (1977) Feeding and digestive organ size in breeding Lesser Snow Geese. Auk 94: 275-282.

Ankney, C. D. and Scott, D. M. (1988) Size of digestive organs in breeding Brown-headed Cowbirds, Molothrus ater, relative to diet. Can. J. Zool. 66: 1254-1257.

Barnes, G. C. and Thomas, V. G. (1987) Digestive organ morphology, diet, and guild structure of North American Anatidae. Can. J. Zool. 65: 1812-1817.

Battley, P. F. and Piersma, T. (2005) Adaptive interplay between feeding ecology and features of the digestive tract in birds. Pp. $201-228$ in J. M. Starck and T. Wang, eds. Physiological and ecological adaptations to feeding in vertebrates. Enfield, NH: Science Publishers.

BirdLife International (2000) Threatened birds of the world. Barcelona and Cambridge, U.K.: Lynx Edicions and BirdLife International.

Black, J. M., Marshall, A. P., Gilburn, A., Santos, N., Hoshide, H., Medeiros, J., Mello, J., Natividad Hodges, C. and Katahira, L. (1997) Survival, movements, and breeding of released Hawaiian Geese: an assessment of the reintroduction program. J. Wildl. Manage. 61: 1161-1173.

Brittas, R., Marcström, V., Kenward, R. E. and Karlbom, M. (1992) Survival and breeding success of reared and wild Ring-necked Pheasants in Sweden. J. Wildl. Manage. 56: 368-376.

Davis, A. and $\mathrm{O}^{\prime}$ Connor, S. (2002) Brown Teal recovery group meeting minutes 2002. Internal report. Wellington, New Zealand: Department of Conservation.

Dekinga, A., Dietz, M. W., Koolhaas, A. and Piersma, T. (2001) Time course and reversibility of changes in the gizzards of red knots alternately eating hard and soft food. J. Exp. Biol. 204: $2167-2173$.

Drobney, R. D. (1984) Effect of diet on visceral morphology of breeding Wood Ducks. Auk 101: 93-98.

DuBowy, P. J. (1985) Seasonal organ dynamics in post-breeding male Blue-winged Teal and Northern Shovellers. Comp. Biochem. Physiol. 82A: 899-906.

Dumbell, G. S. (2000) Brown Teal captive management plan. Threatened species occasional publication 15. Wellington, New Zealand: Department of Conservation.

Goudie, R. I. and Ryan, P. C. (1991) Diets and morphology of digestive organs of five species of sea ducks wintering in Newfoundland. J. Yamashina Inst. Ornithol. 22: 1-8.

Hartman, G. (1985) Foods of male Mallard, before and during moult, as determined by faecal analysis. Wildfowl 36: 65-71.

Hayes, F. N. (1981) The aviculture, re-establishment and status of the New Zealand Brown Teal. Hamilton, New Zealand: Ducks Unlimited Inc.

Heather, B. (1980) Brown Teal, NZ Dotterel, and Variable Oystercatcher: an unusual rock group. Notornis 27: 164-167.

Heitmeyer, M. E. (1988) Changes in the visceral morphology of wintering female Mallards (Anas platyrhynchos). Can. J. Zool. 66: 2015-2018.

Hilton, G. M., Furness, R. W. and Houston, D. C. (2000) The effects of diet switching and mixing on digestion in seabirds. Funct. Ecol. 14: 145-154.

Karasov, W. H. and McWilliams, S. R. (2005) Digestive constraints in mammalian and avian ecology. Pp. 87-112 in J. M. Starck and T. Wang, eds. Physiological and ecological adaptations to feeding in vertebrates. Enfield, NH: Science Publishers.

Kehoe, F. P., Ankney, C. D. and Alisauskas, R. T. (1988) Effects of dietary fiber and diet diversity on digestive organs of captive Mallards (Anas platyrhynchos). Can. J. Zool. 66: 1597-1602.

Klasing, K. C. (1998) Comparative avian nutrition. Wallingford, U.K.: CAB International.

Kristan, D. M. and Hammond, K. A. (2000) Combined effects of cold exposure and sub-lethal intestinal parasites on host morphology and physiology. J. Exp. Biol. 203: 3495-3504. 
Krapu, G. L. (1974) Feeding ecology of Pintail hens during reproduction. Auk 91: 278-290.

Liukkonen-Anttila, T., Putaala, A. and Hissa, R. (1999) Does shifting from a commercial to a natural diet affect the nutritional status of hand-reared Grey Partridges Perdix perdix? Wildl. Biol. 5: 147-156.

Marchant, S. and Higgins, P., eds. (1990) Handbook of Australian, New Zealand and Antarctic birds. Melbourne, Australia: Oxford University Press.

Miller, M. R. (1975) Gut morphology of Mallards in relation to diet quality. J. Wildl. Manage. 39: $168-173$.

Moore, S. J. (2003) Brown Teal (Pateke) diet and its consequences for releases. Unpublished MSc thesis, Massey University, Palmerston North, New Zealand.

Moore, S. J. and Battley, P. F. (2003a) The use of wing remains to determine condition before death in Brown Teal (Anas chlorotis). Notornis 50: 133-140.

Moore, S. J. and Battley, P. F. (2003b) Cockle-opening by a dabbling duck, the Brown Teal. Waterbirds 26: 331-334.

Moss, R. (1972) Effects of captivity on gut lengths in Red Grouse. J. Wildl. Manage. 36: 99-104.

Moss, R. (1983) Gut size, body weight, and digestion of winter foods by grouse and ptarmigan. Condor 85: 185-193.

Moss, R. and Trenholm, I. B. (1987) Food intake, digestibility and gut size in Red Grouse. Br. Poultry Sci. 28: 81-89.

Paganin, M. and Meneguz, P. G. (1992) Gut length of wild and reared Rock Partridges (Alectoris graeca): its role in release success. Gibier Faune Sauvage 9: 709-715.

Piersma, T., Koolhaas, A. and Dekinga, A. (1993) Interactions between stomach structure and diet choice in shorebirds. Auk 110: $552-564$.

Starck, J. M. (1999a) Phenotypic flexibility of the avian gizzard: rapid, reversible and repeated changes of organ size in response to changes in dietary fibre content. J. Exp. Biol. 202: 3171-3179.

Starck, J. M. (1999b) Structural flexibility of the gastro-intestinal tract of vertebrates: implications for evolutionary morphology. Zool. Anz. 238: 87-101.

Starck, J. M. (2005) Structural flexibility of the digestive system of tetrapods: patterns and processes at the cellular and tissue level. Pp. 175-200 in J. M. Starck and T. Wang, eds. Physiological and ecological adaptations to feeding in vertebrates. Enfield, NH: Science Publishers.

van Gils, J. A., Piersma, T., Dekinga, A. and Dietz, M. W. (2003) Cost-benefit analysis of mollusc-eating in a shorebird. II. Optimizing gizzard size in the face of seasonal demands. J. Exp. Biol. 206: 3369-3380.

Williams, M. and Dumbell, G. S. (1996) Brown Teal (Pateke) Anas chlorotis recovery plan. Threatened species recovery plan 19. Wellington, New Zealand: Department of Conservation.

\section{SUZANNE J. MOORE}

Ecology Group, Massey University, Private Bag 11 222, Palmerston North, New Zealand.

Current address: P. O. Box 151, Tuakau, New Zealand. E-mail: suzannemoore@quicksilver. net.nz

PHIL F. BATTLEY

Department of Mathematics and Statistics, University of Otago, P. O. Box 56, Dunedin, New Zealand.E-mail: philbattley@quicksilver.net.nz 